\title{
Medical Waste Management: An Assessment at District-Level Public Health Facilities in Bangladesh
}

\author{
Hasnat Sujon \\ International Centre for Diarrhoeal Disease Research, Bangladesh (icddr,b) \\ Taposh Kumar Biswas \\ International Centre for Diarrhoeal Disease Research, Bangladesh (icddr,b) \\ Aklima Chowdhury \\ Intercontinental Centre for Diarrhoeal Disease Research, Bangladesh (icddr,b) \\ Mahbub Elahi Chowdhury ( $\sim$ melahi@icddrb.org ) \\ https://orcid.org/0000-0001-5690-3303
}

Research article

Keywords: medical waste; healthcare waste; district hospital; mother and child welfare centre; Bangladesh

Posted Date: July 27th, 2020

DOI: https://doi.org/10.21203/rs.3.rs-46040/v1

License: (c) (i) This work is licensed under a Creative Commons Attribution 4.0 International License. Read Full License 


\section{Abstract}

Background Due to the heavy patient-load and various types of services, the public health facilities produce a bulk of medical wastes (MW) in Bangladesh. Improper disposal of MW increases the risk of infection among the healthcare service personnel, patients, and attendants. The current study aimed to assess the practices of MW management and quantify those to find out the gaps in the specific steps of waste management.

Methods As part of a larger intervention study, a facility assessment was conducted during November 2015 to March 2016 at a District Hospital (DH) and a Mother and Child Welfare Centre (MCWC) both being located in the same district, Non-participatory observation of MW management was done using a checklist developed following the Guideline for Medical Waste Management of Bangladesh. Scoring was applied for various activities of MW management performed in the study facilities.

Results The overall scores in bin management, segregation, and collection of wastes were $64.5 \%, 58.1 \%$, and $62.0 \%$ in the $\mathrm{DH}$ and $53.1 \%, 41.5 \%$, and $48.0 \%$ in the MCWC respectively. The performance of operation theatre in MCWC was the lowest among different corners (16.7-36.0\%). Reusable waste was segregated poorly (32\% in $\mathrm{DH}$ and $0 \%$ in $\mathrm{MCWC}$ ), and almost none was shredded (4\% in $\mathrm{DH}$ and $0 \%$ in $\mathrm{MCWC}$ ). The wastes were transported from in-house to out-house temporary storage area in open-bin without any trolley or specific route. Storage area was accessible to unauthorized persons, e.g. waste-picker in $\mathrm{DH}$. While $\mathrm{DH}$ segregated $84 \%$ of its infectious wastes at source, they eventually got mixed-up with other wastes in the storage area and delivered to municipality for dumping. MCWC could segregate only $40 \%$ of its infectious wastes at source and disposed those, using pit method. Both the facilities disposed sharp medical wastes by open-air burning and liquid wastes through sewerage without any treatment.

Conclusions The performance of MW management was poor in both the study facilities. Advocacy to the healthcare personnel and refresher training, along with supportive supervision and monitoring, may improve the situation. Moreover, larger study is needed to find out the reasons behind such poor MW management.

\section{Background}

Medical waste (MW) management is a growing concern worldwide, particularly in developing countries like Bangladesh [1]. As different health concerns compete for limited resources in these countries, MW management remains a less-prioritized activity of the healthcare facilities. Population growth, rapid urbanization, mushrooming of private healthcare facilities, and increasing use of disposable medical equipment are other factors contributing to this burden [2]. The total waste stream produced by healthcare delivery can be categorized as non-hazardous and hazardous waste; $75-90 \%$ of MW are non-hazardous but the remaining 10-25\% contain pathogenic microorganisms and toxic chemicals requiring special treatment to mitigate the environmental and health risks [3]. Although the amounts of MW to be dealt with, in any country are minute compared to the entire quantity of wastes produced, the consequences of medical wastes are far too great if these remain untreated. If the hazardous wastes are dumped with other wastes without proper treatment, the entire waste stream become a potential source of infection [4]. People coming in proximity to these hazardous wastes through generating, handling, or being exposed by other means are vulnerable to serious diseases, like HIV/AIDS, hepatitis B, and hepatitis C, and others [3, 5]. Globally, 1 out of 3 and, in Bangladesh, 9 out of 10 hospitals lack basic MW management services [6].

MW management is a systemic approach from the source to its final destiny through effective segregation, handling, and treatment [7]. An effective MW management system is an integral part of infection prevention measures of a facility and crucially associated with quality of care and safety of both providers and patients, along with the community [8]. The irony of healthcare delivery system in developing countries like Bangladesh is: while the healthcare facilities are entrusted to heal the sickness and maintain wellness, the system itself can become a source of outbreak of various health problems. Proper management of MW can minimize the risk of further burdens both within and outside healthcare facilities by limiting a definitive source of preventable infection [7]. If healthcare delivery system is unable to address the urgent issue of MW management, channels of diseases and epidemic outbreaks would widen [9], thereby the healthcare situation would be like: 'curing at the front door and poisoning at the back door' [10]. The importance of MW management is well-grounded and regarded as an integral part of the healthcare delivery process [11].

At the district level in Bangladesh, there is a District Hospital (DH) and a Mother and Child Welfare Centre (MCWC) under the Ministry of Health and Family Welfare. While all types of secondary healthcare services are provided from the DHs, the MCWCs provide only maternal and child health services, along with family planning services. Thus, the structure, service availability, and human resources are quite distinct in these two types of facilities. However, both the facilities manage referred patients from sub-districts and lower level [12]. A Guideline for Medical Waste Management [11] has been developed by the Ministry of Health and Family Welfare for the healthcare facilities of Bangladesh but successful execution has remain a major concern. 
Several studies have been conducted in Bangladesh to understand the MW management system. These studies focused on quantification and final disposal method of MW and knowledge of staff on and barriers to efficient MW management [13-20]. To find an answer to the existing gap in MW management in Bangladesh, it is imperative to evaluate each and every step of MW treatment properly from its source to the destiny. To the best of our knowledge, until recently, no study thoroughly examined all steps of in- and out-house MW management practices in Bangladesh and quantified the performance of the healthcare facilities according to the standard guideline. The current study assessed the MW management practices in two district-level public healthcare facilities according to the Guideline for Medical Waste Management in Bangladesh. It also documented the existing gaps and shortcomings in implementation of the MW management guideline.

\section{Methods}

\section{Study design}

We conducted a cross-sectional facility assessment from November 2015 to March 2016 as part of a larger intervention study.

\section{Study Settings And Population}

The study was conducted in a 100-bed DH and a 20-bed MCWC located at a district headquarter in Bangladesh. Both the study hospitals were secondary-level public facility. In each of the facilities, cleaners/ayas were assigned to the job of waste management. We assessed the waste management in the emergency room, labour and gynaecology ward, operation theatre (OT), paediatrics ward, pathology unit, and outdoor (antenatal and postnatal care room) of the study facilities separately. In the MCWC, due to unavailability of pathological services and indoor paediatric services there was no paediatrics ward, and pathology unit. Again, emergency services were provided along with antenatal and postnatal care at the same room in outdoor..

\section{Methods Of Data Collection}

To assess the waste management system, we developed a contextualized checklist based on the nature of MW likely to be generated in the study facilities following the Guideline for Medical Waste Management [11] of the government of Bangladesh. Details of the implementation process of the waste management activities in different corners were collected through non-participatory direct observation using the checklist which included in-house and out-house facility waste management sections. Entire MW management consisted of in-house facility waste management, out-house facility waste management and final disposal. In-house facility waste management included process of bin management, segregation of wastes, and waste collection from different wards/rooms. The out-house facility waste management included transportation of waste to the temporary storage area, management of temporary waste storage area, and waste collection process by the municipality/authority. All the processes were again divided into different number of components.

A team consisting of two medical doctors and two trained interviewers was assigned to collect data from the designated hospitals. All the team members were trained thoroughly on the quality and ethical issues regarding data collection.

\section{Scoring System}

Individual scoring was done in different components of MW management, and then average score was calculated. For scoring of bin management and waste collection from the ward/room, full score was provided if all the recommended number of bins of a particular room was managed according to the each component of the waste management guideline but failure to do so for any bin, lower score was given. For example, if 3 bins among recommended 5 were labelled, the maximum score was 5 and the score obtained was 3 . For segregation of waste, score was provided on a scale of 0 to 5 as only five types of waste were produced in both facilities. A score of 5 was given if the bins did not contain mixture of wastes. For partial segregation, the score had been lowered leading to 0 for all five types of waste being disposed in the same-coloured bin.

For components of out-house facility waste management, we observed the availability of equipment, logistics and supplies, along with practices.

\section{Data analysis}

The data were computerized using SPSS Version 21. All the entered data were checked for inconsistency by applying logical conditions. If there was any inconsistency, necessary corrective measures were taken after comparing the entered data with those in the checklist. Percentage of 
scoring was calculated separately for each component of relevant process in every ward/room and then, an overall score was calculated for each process of waste management. For interpretation purpose, we categorized $>80 \%$ scores as high, $50-80 \%$ as moderate, and $<50 \%$ as low.

\section{Results}

\section{In-house facility waste management}

Overall scores in bin management were $64.5 \%$ in $\mathrm{DH}$ and $53.1 \%$ in MCWC. The highest score in bin management was obtained by the labour and gynaecology ward (76.2\%) in DH and outdoor (76.6\%) in MCWC. Although the OT in MCWC obtained only $24.6 \%$ score, other intervened service areas of both $\mathrm{DH}$ and MCWC obtained moderate scores (53.1\%-76.6\%) in bin management. In segregation of wastes, the DH and MCWC obtained $58.1 \%$ and $41.5 \%$ score respectively. Although the outdoor of MCWC obtained $100 \%$ score, the overall score was poor due to very low score in the OT (16.7\%). In the DH, the segregation of wastes was better in OT and outdoor (both scoring $80 \%$ ) compared to the other service areas as each of those obtained a poor score (46.7\% each). Scores in collection of waste varied from $56-68 \%$ in $\mathrm{DH}$ and $36-56 \%$ in $\mathrm{MCWC}$ (Fig. 1).

Component-wise analysis revealed a wide variation among the scores for bin management in both the facilities. Although all the bins in the DH were intact (neither broken nor leaked) and accessible to the patients, none was labelled, and only $44 \%$ were closed with lids. The scores in MCWC were more or less similar with those in the $\mathrm{DH}$. The score on waste management-related 'poster above the bin' was only $10 \%$ in $\mathrm{DH}$ and $0 \%$ in MCWC (Table 1). 
Table 1

Average score (\%) obtained in different segments of in-house facility waste management in DH and MCWC.

\begin{tabular}{|c|c|c|c|c|}
\hline \multirow[t]{3}{*}{ Components of in-house facility waste management } & \multicolumn{4}{|c|}{ Average score obtained } \\
\hline & \multicolumn{2}{|l|}{$\mathrm{DH}$} & \multicolumn{2}{|l|}{ MCWC } \\
\hline & Score (n) & $\%$ & Score $(n)$ & $\%$ \\
\hline \multicolumn{5}{|l|}{ Bin management } \\
\hline Correct in placement & $14(16)$ & 87.5 & $6(9)$ & 66.6 \\
\hline Correct in colour & $25(30)$ & 83.3 & $11(15)$ & 73.3 \\
\hline Closed with lid & $11(25)$ & 44.0 & $9(15)$ & 60.0 \\
\hline Neither leaked nor broken & $30(30)$ & 100.0 & $11(15)$ & 73.3 \\
\hline Cleanliness of bins & $27(30)$ & 90.0 & $11(15)$ & 73.3 \\
\hline Not exceeding capacity & $29(30)$ & 96.6 & $11(15)$ & 73.3 \\
\hline Colour code written & $20(30)$ & 66.6 & $8(15)$ & 53.3 \\
\hline Colour code maintained & $18(30)$ & 60.0 & $9(15)$ & 60.0 \\
\hline Labelled & $0(30)$ & 0.0 & $0(15)$ & 0.0 \\
\hline Accessible for patients & $20(20)$ & 100.0 & $5(5)$ & 100.0 \\
\hline Surrounding cleanliness & $28(30)$ & 93.3 & $12(15)$ & 80.0 \\
\hline Flip-chart/poster available regarding infection prevention & $8(30)$ & 26.6 & $2(15)$ & 13.3 \\
\hline Waste management-related poster above the bin & $3(30)$ & 10.0 & $0(15)$ & 0.0 \\
\hline Overall & $233(361)$ & 64.5 & $95(179)$ & 53.1 \\
\hline \multicolumn{5}{|l|}{ Segregation of waste } \\
\hline General waste-keeping in black bin & $25(30)$ & 83.3 & $10(15)$ & 66.6 \\
\hline Sharp waste-keeping in red bin & $23(25)$ & 92.0 & $5(10)$ & 50.0 \\
\hline Infectious waste-keeping in yellow bin & $21(25)$ & 84.0 & $4(10)$ & 40.0 \\
\hline Re-usable waste-keeping in green bin & $8(25)$ & 32.0 & $0(10)$ & 0.0 \\
\hline Liquid waste-keeping in blue bin/bowl & $12(25)$ & 48.0 & $8(10)$ & 80.0 \\
\hline Re-usable wastes-shredding & $1(25)$ & 4.0 & $0(10)$ & 0.0 \\
\hline Overall & $91(155)$ & 58.1 & $27(65)$ & 41.5 \\
\hline \multicolumn{5}{|l|}{ Waste collection from ward/room } \\
\hline Availability of extra bin to replace the existing bin while emptying & $0(30)$ & 0.0 & $0(15)$ & 0.0 \\
\hline Proper emptying of bins & $30(30)$ & 100.0 & $11(15)$ & 73.3 \\
\hline Cleaning of bins after waste collection & $27(30)$ & 90.0 & $10(15)$ & 66.6 \\
\hline Cleaners wearing protective materials & $10(30)$ & 33.3 & $3(15)$ & 20.0 \\
\hline Cleaners follow proper hand-washing & $26(30)$ & 86.6 & $12(15)$ & 80.0 \\
\hline Overall & $93(150)$ & 62.0 & $36(75)$ & 48.0 \\
\hline
\end{tabular}

Segregation of wastes was the most neglected component in both the facilities. Among the 6 components of segregation of wastes, the DH obtained more than $80 \%$ scores in general, sharp and infectious waste segregation; for other 3 components, viz. segregation of re-usable waste, liquid waste, and shredding of re-usable waste, the scores were quite low ranging from $4-48 \%$. The MCWC failed to obtain any score in segregation or shredding of re-usable waste but scored $80 \%$ in segregation of liquid waste (Table 1). 
Analysis of different components of waste collection from wards/rooms showed proper emptying of bins, cleaning after waste collection, and proper hand-washing practice; these components yielded moderate to high scores in both $\mathrm{DH}(100 \%, 90.0 \%$, and $86.6 \%)$ and $\mathrm{MCWC}$ (73.3\%, $66.6 \%$, and $80.0 \%$ ). Scores in the use of personal protective equipment (PPE) were very low in both the facilities, and zero score was yielded in the availability of extra bin to be replaced with the existing bins (Table 1).

\section{Out-house Facility Waste Management}

There was no trolley or hand-cart for carrying waste bins in any study facility for transportation of waste from in-house place of generation to temporary storage area, and the route of transportation was not separated. Among 5 bins, 3 in DH and 1 in MCWC were covered with lids during transportation. Among the advocated 11 components, DH could meet only 4, in contrast to 8 components in MCWC regarding management of the temporary waste storage area. Although the location of the temporary storage area was far from the food preparation area and had proper light with passive ventilation; cleaning and firefighting equipment were unavailable in both facilities. The dedicated temporary waste storage area in DH had no good drainage system or water supply. Unauthorized persons, e.g. scavengers and waste-pickers could easily get access to the area. In contrast, although the temporary waste storage area of MCWC had drainage system and water supply, wastes were sometimes stored for more than 24 hours. However, unlike $\mathrm{DH}$, unauthorized persons could not get access to that area of MCWC. Among the 8 components of waste-collection process by municipality/authority, DH and MCWC followed 2 and 3 components respectively. Both the facilities transported waste to the temporary storage area within short time. Although the $\mathrm{DH}$ showed better segregation in in-house waste management, all of these segregated wastes got mixed in the temporary storage area, and municipality/authority collected those without any colour code whereas MCWC supplied the segregated wastes to municipality/authority as per colour code, although adequate segregation was not done properly. In none of the facilities, cleaners used any protective materials (e.g. hand-gloves, shoes, long-sleeve shirts). Although drivers' areas were separated from the waste-carrying area, none of the vans were covered or locked, or properly cleaned every day after carrying the wastes (Table 2 ). 
Out-house facility waste management in temporary waste storage area in DH and MCWC.

\begin{tabular}{|c|c|c|}
\hline Components of out-house facility waste management of temporary waste storage area & $\mathrm{DH}$ & MCWC \\
\hline \multicolumn{3}{|l|}{ Transportation of waste to temporary waste storage area } \\
\hline Trolley available for carrying waste bin & No & No \\
\hline Waste bin covered with lid during transportation & Partially ${ }^{a}$ & Barely ${ }^{b}$ \\
\hline Specific route for transportation of wastes & No & No \\
\hline \multicolumn{3}{|l|}{ Temporary waste storage area management } \\
\hline Impermeable, hard-standing floor with good drainage system & No & Yes \\
\hline Water supply for cleaning purpose & No & Yes \\
\hline Availability of cleaning equipment, sand and firefighting equipment & No & No \\
\hline Inaccessibility to unauthorized persons, animals and insects & No & Yes \\
\hline Proper light, passive ventilation & Yes & Yes \\
\hline Location of the area far from the food preparation area & Yes & Yes \\
\hline Bins are covered with lids & No & Yes \\
\hline Under lock and key/door is closed & No & Yes \\
\hline Easy access for vans/trucks to take wastes & Yes & Yes \\
\hline Waste not stored more than 24 hours & Yes & No \\
\hline For emergency, waste stored for more than 24 hours, informing higher authority and ensuring no harm to others & - & No \\
\hline \multicolumn{3}{|l|}{ Waste collection process by municipality/authority } \\
\hline Collection of waste as per colour code from facility & No & Yes \\
\hline Collection of waste in a covered van & No & No \\
\hline The drivers' area totally separated from waste-carrying area & Yes & Yes \\
\hline Transport within short time & Yes & Yes \\
\hline Cleaners wearing protective cloths & No & No \\
\hline Waste in the van is locked & No & No \\
\hline Van is air-conditioned to keep waste for a long time & No & No \\
\hline Van is properly cleaned every day after carrying waste & No & No \\
\hline DH = District Hospital, MCWC = Mother and Child Welfare Centre & & \\
\hline
\end{tabular}

\section{Final Disposal Of Medical Wastes}

The Guideline for Medical Waste Management of Bangladesh prescribed different disposal methods for different segregated wastes. In both DH and MCWC, final disposal of MW was more or less similar. Incinerator was not available in any of the facilities. Both the facilities followed openair burning for sharp wastes. MCWC disposed infectious wastes by pit method but those that got mixed with other wastes in DH were dumped as general waste. Both the facilities used public dustbin of municipality to dispose general waste and sewerage system to dispose liquid waste. There was no system of recycling re-usable wastes (Table 3). 
Table 3

Final methods of medical waste disposal in DH and MCWC

\begin{tabular}{|c|c|c|c|}
\hline \multirow[t]{2}{*}{ Type of waste } & \multirow[t]{2}{*}{ Recommended method(s) for waste disposal } & \multicolumn{2}{|c|}{ Scenario in } \\
\hline & & $\mathrm{DH}$ & MCWC \\
\hline \multirow[t]{3}{*}{ Sharp waste } & Incinerator & $x$ & $x$ \\
\hline & Open-air burning (making a hole) & $\sqrt{ }$ & $\sqrt{ }$ \\
\hline & Pit method & $\sqrt{ }$ & $x$ \\
\hline \multirow[t]{3}{*}{ Infectious waste } & Pit method & $x$ & $\sqrt{ }$ \\
\hline & Deep burial & $x$ & $x$ \\
\hline & Incinerator & $x$ & $\mathrm{x}$ \\
\hline \multirow[t]{3}{*}{ Recyclable waste } & Shredded before disposal & $x$ & $x$ \\
\hline & Re-use by disinfection & $x$ & $\mathrm{x}$ \\
\hline & Re-use by autoclaving & $x$ & $x$ \\
\hline General waste & Dumping in municipal public dustbin & $\sqrt{ }$ & $\sqrt{ }$ \\
\hline Liquid waste & Sewerage system & $\sqrt{ }$ & $\sqrt{ }$ \\
\hline DH = District Hospi & al, MCWC = Mother and Child Welfare Centre & & \\
\hline
\end{tabular}

\section{Discussion}

The practices of MW management in both the study facilities were clearly insufficient and poor. While every recommended procedure of MW management needs to be followed step by step, both the facilities performed, on an average, only about half of the recommended activities. The inadequacy in exercising the MW treatment was quite distinct between the facilities. While MCWC grossly lacked in-house facility waste management, DH performed relatively poor in out-house facility waste management. Absence of labelling, written colour code, and instruction may have augmented to improper use of coloured bins. Inadequate segregation of wastes at source and absence of shredding of re-usable items, along with defective waste transportation and management of temporary waste storage area made the whole waste management system injurious to the human and environmental health. Absence of PPE created higher risk to the personnel involved in the MW management system.

Initial stage of waste management is bin management which was moderate in both the facilities. Six colour-coded bins are recommended for healthcare facilities in Bangladesh-black for general waste, red for sharps, yellow for infectious waste, green for re-usable waste, blue for liquid waste, and silver for radioactive waste [11]. As no radioactive waste was generated in any of the study facilities, silver bin was not there. In developing countries like Bangladesh, usually marginalized, uneducated and economically-vulnerable personnel are engaged in waste management [2]. Absence of labelling and inadequate instruction (flip-chart/poster), coupled with absence of training, may contribute to mismanagement of the bins by the cleaners, which has been reported by other studies $[15,16,21]$. In addition, people attending the public healthcare facilities of Bangladesh are largely non-literate. Even educated patients and their attendants may not know the significance of colour code without instruction. Accessible bins without written colour code and instruction may also encourage people to dispose wastes indiscriminately, which can make the segregation of waste at source a challenging task [22]. While transporting the bins to temporary waste storage area to be emptied, the vacant positions is supposed to be replaced by extra bins, which both the facilities lacked. As a result, people had to dispose wastes openly or in left-out bins without any regard to colour code.

An MW management system with inadequate segregation of infectious waste can be translated as a defective system as a whole. Waste segregation at source through proper use of bins is essential to avoid mixing of infectious waste with other non-hazardous wastes, which acts as a strong barrier against making the entire waste stream hazardous [3]. We have observed poor infectious waste segregation, particularly in MCWC. As the entire infectious wastes could not be segregated, other non-hazardous wastes were mixed with the non-segregated infectious waste. Segregation and shredding of re-usable waste was another neglected issue in both the facilities. An effective waste management system is supposed to follow the 3R (Reduce, Recycle, and Reuse) norm [2]. Whereas recycling and re-using some wastes, like paper and hardboard, are economically beneficial, shredding of certain re-usable wastes, e.g. saline set and syringes, gives a protection against collection and reselling of these equipment.

As OTs produce one-third of all MW generated in a facility [23], the shortcomings in all components of in-house facility waste management is of particular importance. Being the centre of lifesaving surgeries, ineffective bin management, waste segregation, and collection in OTs put the 
lives of people at risk of hospital-acquired infections.

A separate route is recommended to be used in a specific time of the day to carry covered waste to temporary waste storage area in a designated trolley or handcart to minimize the risk of exposure to hospital staff, patients, and visitors, none of which was maintained in both facilities under study. Waste transportation in open bins may result in spillage. The cleaners handled and disposed the wastes without any PPE, which exposed them to high risk of infections [24]. Unrestricted access of unauthorized persons, e.g. waste-pickers and scavengers is another major issue. As facilities do not shred re-usable items, e.g. syringes and saline bags, waste-pickers can collect them from the temporary waste storage area. They handle these items in bare hands and sell them in the local marker [17]. If improperly treated and re-used, these equipment may cause life-threatening diseases, including hepatitis $B$, hepatitis $C$, and HIV/AIDS. On an average, 2.88 injections are received by an individual per year in developing and transitional countries like Bangladesh, of which 5.5\% are administered with a re-used syringe [25]. Several years ago, a black market of these infected items was discovered in Gujarat of India, which eventually claimed more than 50 lives [26].

We observed the global concern: 'waste is sometimes treated without being segregated, and segregated waste is often not treated' [6]. In our study, the problem was quite distinct in the facilities, the DH segregated most of its waste at the point of generation but the cleaners delivered all the wastes mixed together to the municipality with no regard to colour code, except the sharps. This signifies a lack of knowledge rather than a lack of will among the cleaners. MCWC, however, could segregate only a limited quantity of its wastes at source and delivered those to the municipality with colour code. While their effort should be commended, other wastes were also mixed with infectious waste, as only less than half of the infectious wastes were segregated at source. The municipality/authority that collected those wastes for disposal also did not follow most of the guidelines. As a result, the whole lot of wastes became potentially infectious.

While both the facilities had procedures in place to dispose sharp and general wastes, they gave little attention to proper disposal of infectious or recyclable waste. Both of the facilities usually used the municipality dustbin to dump the general waste. Infectious waste was dumped in the municipality dustbin, along with the general waste due to absence of procedure to dispose infectious waste, low waste segregation at source, and eventual mixing of wastes in temporary waste storage area. This type of erratic handling and indiscriminate disposal of MW increase the risk of human contact with hazardous waste and expose the entire community resulting in a risk of environmental tragedy. While incinerator remains a viable option for waste disposal (though criticized for its harmful effects in the environment) in developing countries, including Bangladesh, none of the study facilities was equipped with it. The dumping of infectious and liquid wastes without any treatment has long been discussed for their detrimental effects on the environment $[2,5,13,21]$.

The need for proper waste management to protect the health of care providers and patients and prevent environmental tragedy is imperative. A significant number of studies conducted in Asia and Africa looked into the issue of the underlying causes of improper waste management [2, 9, 15]. Economic condition of a country, despite policy, has been directly linked with the level of MW management [1]. Lack of training is another major barrier to effective waste management. Incorporating all staff members of a facility, including doctors, nurses, paramedics, and cleaners were suggested for a whole-of-the-facility approach to waste management. Facilities should emphasize on waste reduction as this results in less workload [2]. Lack of human resources in healthcare facilities, along with managerial weakness, sub-optimal supervision, and confusion over allocation of duty and responsibility, are other causative factors behind inefficient MW management [22]. While the need for managerial strength and training should be the central issue in the implementation of proper MW management, non-compliance and neglect in some facilities regarding this issue is also reported [27]. Initiatives should be taken immediately to improve the motivation for the staff, monitoring and supervision system to implement waste management guidelines at every stage. Although MW management is not completely risk-free, some low-cost interventions can bring good result, e.g. awareness-building among people attending hospital, supply of PPE and equipment, use of instructional posters, etc. [1]. All cleaners should be screened and vaccinated. The final waste disposal method should be developed considering the safety, cost-effectiveness, and local technology [4, 13].

\section{Limitations Of The Study}

The study was conducted only in two secondary-level public healthcare facilities in Bangladesh, and the underlying reasons for improper management were not well-explored. Although waste production may differ in facilities of other tiers, this study tried to identify the areas to improve in everyday practice. Further studies, including qualitative approach, is needed for exploring reasons behind the current situation and to find out interventions to address the gaps.

\section{Conclusion}

Medical wastes involve a potential source of injury, infection, and environmental damage. Although the consequences of improper MW management are highly negative, only a small percentage of MW needs special consideration. Findings of the study do not reveal proper compliance with the Guideline for Medical Waste Management in public facilities in Bangladesh. Most of the identified gaps can be addressed with low investment and high commitment. Putting administrative and institutional mechanism in place, with effective monitoring and

Page $9 / 12$ 
supervision, may alter the situation to safeguard the environmental and human health. In addition, necessary budget allocation for continuous advocacy and periodic refresher training of the relevant staff should be ensured by the authority for better MW management in health facilities.

\section{Abbreviations}

MW: Medical waste; DH: District Hospital; MCWC: Mother and Child Welfare Centre; OT: Operation theatre; ANC: Antenatal care; PNC: Postnatal care

\section{Declarations}

\section{Ethical approval and consent to participate}

Ethical approval to conduct the study was obtained from the Ethics Review Committee of the International Centre for Diarrhoeal Disease Research, Bangladesh (icddr,b). Informed written consents were obtained from the heads of the respective heath facilities before starting the observation.

\section{Consent for publication}

Consent for publishing non-identifiable service providers' data was obtained from heads of the health facilities.

\section{Availability of data and materials}

The detailed dataset is available with MEC, the Principal Investigator of the main study. A copy of the original data is also stored in the data archive of icddr,b. These data are not publicly available. However, non-identifiable data can be accessible upon request subject to approval of the Research Administration Department of icddr,b.

\section{Competing interests}

The authors declare that none of the authors have any competing interests.

\section{Funding}

This study was fully funded by the United States Agency for International Development (USAID) under the TRAction project of icddr,b through University Research Co., LLC (URC), Sub-agreement No. FY11-G04-699 under Cooperative Agreement No. GHS-A-00- 09-00015-00; icddr,b also acknowledges the contribution of the current donors providing unrestricted support to icddr,b that includes the Government of the People's Republic of Bangladesh; Global Affairs Canada (GAC); Swedish International Development Cooperation Agency (Sida), and the Department for International Development (UK Aid).

\section{Authors' contributions}

HS participated in data analysis, interpretation of the results, and drafted the manuscript. TKB reviewed the manuscript and gave substantial inputs in writing. AC collected data and participated in analysis and report writing. MEC generated the idea of creating score on medical waste management at the health facilities and drafted the manuscript. He had also conceptualized the main study, contributed in writing and critically reviewed the manuscript.

\section{Acknowledgements}

The authors are grateful to the Ministry of Health and Family Welfare of the Government of Bangladesh for allowing us to conduct the study in their health facilities. We also acknowledge the support of 'MaMoni' project of Save the Children for their cooperation during implementation of the study.

\section{Authors' information}

HS is a researcher and is affiliated with the International Centre for Diarrhoeal Disease Research, Bangladesh (icddr,b), Dhaka, Bangladesh. TKB is also a researcher and was affiliated with icddr,b during the study. AC is a research officer at icddr,b. The corresponding author MEC is a Scientist at icddr,b.

\section{References}

1. Caniato M, Tudor T, Vaccari M. International governance structures for health-care waste management: A systematic review of scientific literature. J Environ Manage. 2015;153:93-107. 
2. Ali M, Wang W, Chaudhry N, Geng Y. Hospital waste management in developing countries: A mini review. Waste Manag Res. 2017;35:58192.

3. World Health Organization. Safe management of wastes from health-care activities Second edition. 2nd edition. Geneva; 2014. https://apps.who.int/iris/bitstream/handle/10665/85349/9789241548564_eng.pdf;jsessionid=9F3B3B0D25A0069FD96428A9DDD35F3E? sequence=1. Accessed 12 Jun 2020.

4. Eleyan D, Al-Khatib IA, Garfield J. System dynamics model for hospital waste characterization and generation in developing countries. Waste Manag Res. 2013;31:986-95.

5. Hossain MS, Santhanam A, Nik Norulaini NA, Omar AKM. Clinical solid waste management practices and its impact on human health and environment - A review. Waste Manag. 2011;31:754-66.

6. World Health Organization, United Nations Children's Fund. WASH in health care facilities: global baseline report 2019. Geneva; 2019. http://apps.who.int/bookorders. Accessed 9 Jun 2020.

7. World Health Organization. Safe management of wastes from health-care activities: a summary. Geneva; 2017. http://apps.who.int/bookorders. Accessed 9 Jun 2020.

8. World Health Organization, Regional Office for South-East Asia. Regional workshop on health-care waste management. 2012. https://apps.who.int/iris/handle/10665/206206. Accessed 10 Jun 2020.

9. Oyekale AS, Oyekale TO. Healthcare waste management practices and safety indicators in Nigeria. BMC Public Health. 2017;17:740.

10. Harhay MO, Halpern SD, Harhay JS, Olliaro PL. Health care waste management: A neglected and growing public health problem worldwide. Trop Med Int Heal. 2009;14(11):1414-7.

11. Ministry of Health. and Family Welfare PR of B. Guideline for medical waste management. Dhaka; 2016.

12. Chowdhury ME, Roy L, Biswas TK, Rahman M, Akhter S, Al-Sabir A. A needs assessment study for emergency obstetric and newborn care (EmONC) services in 24 districts of Bangladesh. Dhaka; 2014.

13. Hasan MM, Rahman MH. Assessment of Healthcare Waste Management Paradigms and Its Suitable Treatment Alternative: A Case Study. J Environ Public Health. 2018;6879751.

14. Unicomb L, Horng L, Alam MU, Halder AK, Shoab AK, Ghosh PK, et al. Health-care facility water, sanitation, and health-care waste management basic service levels in Bangladesh: Results from a nation-wide survey. Am J Trop Med Hyg. 2018;99(4):916-23.

15. Sarker MAB, Harun-Or-Rashid M, Hirosawa T, Hai MSBA, Siddique MRF, Sakamoto J, et al. Evaluation of knowledge, practices, and possible barriers among healthcare providers regarding medical waste management in Dhaka, Bangladesh. Med Sci Monit. 2014;20:2590-7.

16. Patwary MA, O'Hare WT, Sarker MH. Assessment of occupational and environmental safety associated with medical waste disposal in developing countries: A qualitative approach. Saf Sci. 2011;49(8-9):1200-7.

17. Akter N, Filho WL, Ali MR. An overview of approaches towards improving in-house Medical Waste Management in Bangladesh: A pilot research. Int J Environ Waste Manag. 2010;6(1-2):162-82.

18. Patwary MA, O'Hare WT, Street G, Maudood Elahi K, Hossain SS, Sarker MH. Quantitative assessment of medical waste generation in the capital city of Bangladesh. Waste Manag. 2009;29(8):2392-7.

19. Alam MM, Sujauddin M, Igbal GMA, Huda SMS. Report. Healthcare waste characterization in Chittagong Medical College Hospital, Bangladesh. Waste Manag Res. 2008;26(3):291-6.

20. Hassan MM, Ahmed SA, Rahman KA, Biswas TK. Pattern of medical waste management: Existing scenario in Dhaka City, Bangladesh. BMC Public Health. 2008;8:36.

21. Khan BA, Cheng L, Khan AA, Ahmed H. Healthcare waste management in Asian developing countries: A mini review. Waste Manag Res. 2019;37:863-75. doi:10.1177/0734242X19857470.

22. Oroei M, Momeni M, Palenik CJ, Danaei M, Askarian M. A qualitative study of the causes of improper segregation of infectious waste at Nemazee Hospital, Shiraz, Iran. J Infect Public Health. 2014;7:192-8.

23. Wormer BA, Augenstein VA, Carpenter CL, Burton PV, Yokeley WT, Prabhu AS, et al. The green operating room: Simple changes to reduce cost and our carbon footprint. Am Surg. 2013;79:666-71.

24. Amanullah A, Uddin J. Dynamics of health behavior regarding hospital waste management in Dhaka, Bangladesh: A dysfunctional health belief model. Int Q Community Health Educ. 2008;29(4):363-80.

25. Pépin J, Chakra CNA, Pépin E, Nault V. Evolution of the global use of unsafe medical injections, 2000-2010. PLoS One. 2013;8(12):e80948.

26. Solberg KE. Trade in medical waste causes deaths in India. Lancet. 2009;373(9669):1067.

27. Hangulu L, Akintola O. Perspectives of policy-makers and stakeholders about health care waste management in community-based care in South Africa: A qualitative study. BMC Health Serv Res. 2017;17(1):290. 
Figures

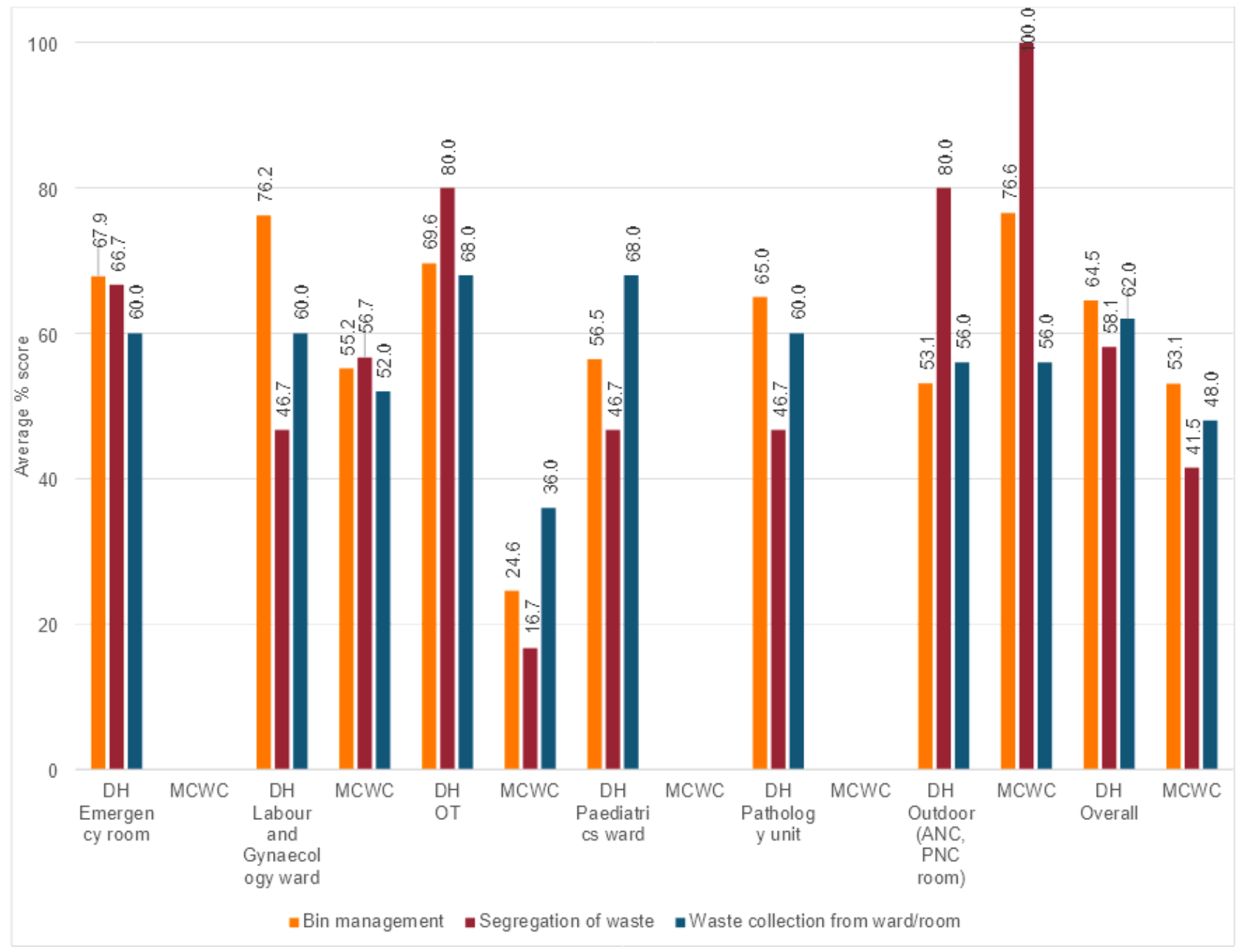

Figure 1

Average \% score obtained in in-house facility waste management by different wards/rooms Legend: DH=District Hospital, MCWC=Mother and Child Welfare Centre, OT=Operation theatre, ANC=Antenatal care, PNC=Postnatal care 